\title{
Papilla of the Tongue
}

National Cancer Institute

\section{Source}

National Cancer Institute. Papilla of the Tongue. NCI Thesaurus. Code C33258.

Numerous, tiny, vertical projections on the anterior two thirds of the dorsal side of the tongue that consist of four types: filiform, fungiform, foliate, and circumvallate. 